\title{
Elective lymph node irradiation late course accelerated hyper-fractionated radiotherapy plus concurrent cisplatin-based chemotherapy for esophageal squamous cell carcinoma: a phase II study
}

Dongqing Wang ${ }^{1}$, Jiali Yang ${ }^{2}$, Jingyu Zhu ${ }^{3}$, Baosheng Li ${ }^{1 *}$, Limin Zhai ${ }^{1}$, Mingping Sun ${ }^{1}$, Heyi Gong ${ }^{1}$, Tao Zhou', Yumei Wei ${ }^{1}$, Wei Huang ${ }^{1}$, Zhongtang Wang ${ }^{1}$, Hongsheng $\mathrm{Li}^{1}$ and Zicheng Zhang ${ }^{1}$

\begin{abstract}
Background: In this phase II study, we evaluated the efficacy, toxicity, and patterns of failure of elective lymph node irradiation (ENI) late course accelerated hyper-fractionated radiotherapy (LCAHRT) concurrently with cisplatin-based chemotherapy (CHT) for esophageal squamous cell carcinoma (ESCC).

Methods: Patients with clinical stage II-IVa $\left(T_{1-4} N_{0-1} M_{0}\right.$ or $\left.M_{1 a}\right)$ ESCC were enrolled between 2004 and 2011. Radiation therapy (RT) comprised two courses: The first course of radiation covered the primary and metastatic regional tumors and high risk lymph nodal regions, given at 2 Gy per fraction for a dose of $40 \mathrm{~Gy}$. In the second course, LCAHRT was delivered to the boost volume twice a day for an additional 19.6 Gy in 7 treatment days, using 1.4 Gy per fraction. Two cycles of CHT were given at the beginning of RT.
\end{abstract}

Results: The median age and Karnofsky performance status were 63 years and 80, respectively. The American Joint Committee on Cancer stage was II in 14 (20.6\%) patients, III in 32 (47.1\%), and IV $\mathrm{I}_{\text {in }} 22$ (32.3\%). With a median follow-up of 18.5 months, the overall survival at 1-, 3-, 5-year were $75.5 \%, 46.5 \%, 22.7 \%$ for whole group patients, versus $78.6 \%, 49.4 \%, 39.9 \%$ for patients with stage II-III. The patterns of first failure from local recurrence, regional failure, and distant metastasis were seen in $20.6 \%, 17.6 \%$, and $19.1 \%$, respectively. The most frequent acute high-grade ( $\geq 3$ ) toxicities were esophagitis and leucopenia, occurred in $26.4 \%$ and $32.4 \%$.

Conclusions: ENI LCAHRT concurrently with CHT was appeared to be an effective regimen for ESCC patient with a favorable and tolerated profile. Further observation with longer time and randomized phase III trial is currently underway.

Trial registration: ChiCTR-TRC-09000568

Keywords: Esophageal squamous cell carcinoma, Elective lymph node irradiation, Chemoradiotherapy

\footnotetext{
*Correspondence: baoshli@yahoo.com

'Department of Radiation Oncology, Shandong Cancer Hospital, Shandong

Academy of Medical Sciences, Jinan, China

Full list of author information is available at the end of the article
} 


\section{Background}

Based on the results of the Radiation Therapy Oncology Group (RTOG) phase III intergroup trial 85-01 and 95-04, the standard therapy for patients with localized esophagus carcinoma selected for nonsurgical treatment is radiation therapy (RT) plus concurrent chemotherapy $[1,2]$. In RTOG $85-01$, combined therapy significantly increased 5-year overall survival (OS) to $26 \%$ (95\% confidence interval $[\mathrm{CI}], 15 \%-37 \%)$ compared with RT alone. However, the incidence of local/regional failure and local/ regional persistence of disease was high up to $45.9 \%$ [1]. In an attempt to improve these results, RTOG 95-04 increased radiation dose from 50.0 Gy to $64.8 \mathrm{~Gy}$, however, intensification of the radiation dose did not improve local/regional control or survival [2]. Although the reason for the lack of benefit using higher dose is unclear, a significant prolongation of treatment time may have contributed, in part, to this result [2].

Several animal experiments and clinical investigations have shown that accelerated proliferation of surviving tumor clonogen during a standard schedule of RT is one of the major reasons for treatment failure [3,4]. It is postulated theoretically that a shortened irradiation course, still keeping the total radiation dose, or increased dose of radiation delivered in the late course of the treatment would improve local control for esophageal carcinoma by overcoming the deleterious effects of accelerated repopulation. Clinical data from China [5] has shown late course accelerated hyperfractionated radiotherapy (LCAHRT) improved the 5-year OS (odds ratio $[\mathrm{OR}]=2.93,95 \% \mathrm{CI}: 2.15-4.00$, $\mathrm{p}<0.00001)$ and 5-year local control $(\mathrm{OR}=3.96,95 \%$ CI: $2.91-5.38, \mathrm{p}<0.00001)$ than standard fractionated RT in the localized esophageal carcinoma. Clinical investigation in nasopharyngeal [6,7] and lung carcinoma [8] also displayed promising treatment outcome.

For esophageal squamous cell carcinoma (ESCC), lymph nodal failure remains a major reason for poor prognosis. Since the early 1980s, Japanese surgeons have practiced 3field regional lymph node dissection for esophageal cancer and led to an improved survival $[9,10]$. It is thought that prophylactic 3-field lymph node dissection improves the survival rate by eliminating micrometastases and reducing the regional lymph node recurrence rate. In accordance with the concept of 3-field lymph node dissection in curative surgery, elective nodal irradiation (ENI) has been adopted for definitive chemoradiotherapy in Japan. Although, the benefit of ENI for ESCC remains controversial, recently studies from Japan $[11,12]$ have confirmed ENI was effective for preventing regional and distant nodal failure in patients with esophageal carcinoma undergoing concurrent chemoradiation.

In randomized clinical trials, no consistent benefit was seen for any specific chemotherapy regimens for locally advanced ESCC. Cisplatin is one of the most active agents, with a single agent response rate consistently in the range of $20 \%$ or greater. Older agent 5 -fluorouracil and newer agents such as capecitabine, pemetrexed, were reported effectiveness for locally advanced ESCC [13].

Based on above thinking, our institution had engaged in clinical trials of ENI LCAHRT concurrently with cisplatinbased chemotherapy (CHT) for ESCC since 2004. The results of our phase I studies [14,15] demonstrated that this treatment scheme was feasible and tolerated, and the treatment outcomes were encouraging. The results with longer follow-up are now reported in the present study.

\section{Methods}

\section{Patients population}

Sixty-eight ESCC patients receiving ENI LCAHRT concurrently with CHT were enrolled from January 2004 to November 2011. Enrollment was limited to clinical stage $\mathrm{T}_{1}$ to $\mathrm{T}_{4}, \mathrm{~N}_{0 / 1}, \mathrm{M}_{0 / 1 \mathrm{a}}$ of primary ESCC located at cervical-, upper-, mid-, or distal-esophagus, according to American Joint Committee (AJCC) tumor-node-metastasis (TNM) system (2002). Eligibility and exclusion criteria were seen below. The protocol was approved by our institutional review board, and written informed consent was obtained from all patients.

\section{Eligibility criteria}

The eligibility criteria were as following: (1) a Karnofsky Performance Status (KPS) $\geq 70$; (2) patients $\leq 75$ years old; (3) histologically confirmed ESCC with the previously untreated; (4) TNM stage for II, III, and IV $\mathrm{a}_{\mathrm{a}}$ (cervical or celiac node metastasis, not include organ metastasis according to AJCC 2002); (5) weight loss $\leq 5 \%$; (6) life expectancy $\geq 3$ months; (7) absolute white blood cell count $\geq 4000 / \mathrm{ml}$, platelets $\geq 100,000 / \mathrm{ml}$, total bilirubin level $\leq 1.5 \mathrm{mg} / \mathrm{dl}$, serum creatinine level $\leq 1.5$ times the upper limit of normal, and aspartate/alanine aminotransferase levels $\leq 2.5$ times the upper limit of normal. The TNM stage was assessed by enhanced computed tomography (CT) and/or combined with ${ }^{18} \mathrm{~F}$-fluorodeoxyglucose position emission tomography/computed tomography $\left({ }^{18} \mathrm{~F}\right.$-FDG PET/CT).

\section{Exclusion criteria}

Exclusion criteria were distant organ metastases, radiographic or bronchoscopic evidence of esophageal peroration, the minimum lumen size less than $5 \mathrm{~mm}$, and some other serious underlying medical conditions such as significant cardiac disease, uncontrolled diabetes, and previous evidence of chemotherapy or RT.

\section{Pretreatment evaluation}

Pretreatment evaluation included a complete history and physical examination, assessment of KPS and quality of life, serum chemistry profile, complete blood cell count, chest $\mathrm{x}$-ray, ECG, endoscopy with biopsy. In order to exclude 
patients with distant organ metastases, pretreatment evaluation also included upper gastrointestinal, chest, and abdominal CT scan, bone scan with single photon emission computed tomography, magnetic resonance imaging scan of the brain and neck, or a whole body ${ }^{18}$ F-FDG PET/CT scan.

\section{Chemoradiotherapy}

Details of LCAHRT were published previously [14,15]. Briefly, the radiation was carried out by $6 \mathrm{MV}$ or $15 \mathrm{MV}$ $\mathrm{X}$-ray using a two-course irradiation schedule: the first course of radiation covered the primary tumors and metastatic regional lymph node(s) and high risk lymph nodal regions (HRLNR), given at 2 Gy per fraction, 5 days a week for a dose of 40 Gy in 20 fractions; the second course of radiation was delivered to the boost volume for an additional dose of 19.6 Gy twice a day in 14 fractions within 7 days using 1.4 Gy per fraction with a 6 $\mathrm{h}$ minimal interval between fractions. The total dose delivered of the two-course irradiation would be $59.6 \mathrm{~Gy} /$ 34 fractions in 5.4 weeks. Accelerated radiation (1.4 Gy per fraction) was used in this protocol in an effort to prevent the late toxicities of mormal tissues. The gross tumor volume included primary cancer $\left(\mathrm{GTV}_{\mathrm{p}}\right)$ and metastatic lymph nodes $\left(G_{T} V_{n}\right)$. The planning target volume (PTV) of the first course $\left(\mathrm{PTV}_{1}\right)$ was defined as $\mathrm{GTV}_{\mathrm{p}}$ adding a $5 \mathrm{~cm}$ margin superiorly and inferiorly and $1 \mathrm{~cm}$ laterally, and $\mathrm{GTV}_{\mathrm{n}}$ with a $0.8 \mathrm{~cm}$ margin, as well as HRLNR adding a $0.8 \mathrm{~cm}$ margin. The PTV of the second course $\left(\mathrm{PTV}_{2}\right)$ was shortened along the superior and inferior ends of $\mathrm{GTV}_{\mathrm{p}}$ with $3 \mathrm{~cm}$ margins, whereas the width of fields remained $1 \mathrm{~cm}$, as well as $G_{T V}$ adding a $0.8 \mathrm{~cm}$ margin. However, the HRLNR were spared.

The chemotherapeutic regimens in present study consisted of cisplatin $25 \mathrm{mg} / \mathrm{m}^{2} /$ day i.v. on days $1-3$ plus 5 -FU $600 \mathrm{mg} / \mathrm{m}^{2} / 24 \mathrm{~h}$ by continuous infusion on days $1-5$ or plus capecitabine $1000 \mathrm{mg}$ twice daily with a $12 \mathrm{~h}$ interval on days $1-14$ or plus pemetrexed $400 \mathrm{mg} / \mathrm{m}^{2}$ on days 1 of a 21-day cycle [14,15]. Two cycles of concurrent chemotherapy were administrated during the process of RT. The choice of chemotherapy regimens for this study was dependent on the economic situation of patients and their voluntary.

\section{Treatment-related toxicity assessment and follow-up}

Treatment-related toxicity assessment was performed at least weekly during treatment, 4 weeks after completion of therapy, every 3 months for 2 years, and every 6 months thereafter using the National Cancer Institute Common Toxicity Criteria (version 3.0). A full history and physical examination, as well as repeat blood work were recorded at these visits. A Spiral CT-scans of the neck, chest, and abdominal were obtained at every follow- up examination to monitor morphological changes in normal tissue structure with respect to radiation-induced toxicity and to evaluate the status of locoregional and distant disease.

\section{End points and statistics}

The primary end point for this study was OS. Survival was measured from the beginning of RT until the last follow-up or death. The secondary end points were treatment-related toxicity, and patterns of failure, included local recurrence (primary tumor), regional failure (lymph nodes), locoregional failure (local recurrence plus regional failure) and distant metastasis. The survival analysis was performed by the actuarial Kaplan-Meier method, and differences between the curves were analyzed by using the log-rank test. Analysis of patterns of failure was performed by using crude calculations.

\section{Results}

\section{Patient-, tumor- and treatment-related characteristics}

Sixty-eight patients (male/female 58/10; cervical/upper/ mid/lower 8/24/27/9) were enrolled in the study. All patients were followed until death or the time of analysis. The age ranged from 40 to 75 years (median, 63 years). The KPS was evaluated as 70-100 (median, 80). Fourteen patients had stage II, 32 stage III, and 22 stage IV $_{\mathrm{a}}$. The distribution of TNM stage for enrolled patients from 2004 to 2011 was displayed in Figure 1. Patient-, tumor- and treatment-related characteristics were summarized in Table 1.

\section{Survival}

The median survival was 34.4 months (95\% CI $19.1-$ 49.6 months) for whole group patients, and the 1-, 3-, 5year OS were $75.5 \%, 46.5 \%$, 22.7\%, respectively (Figure 2).

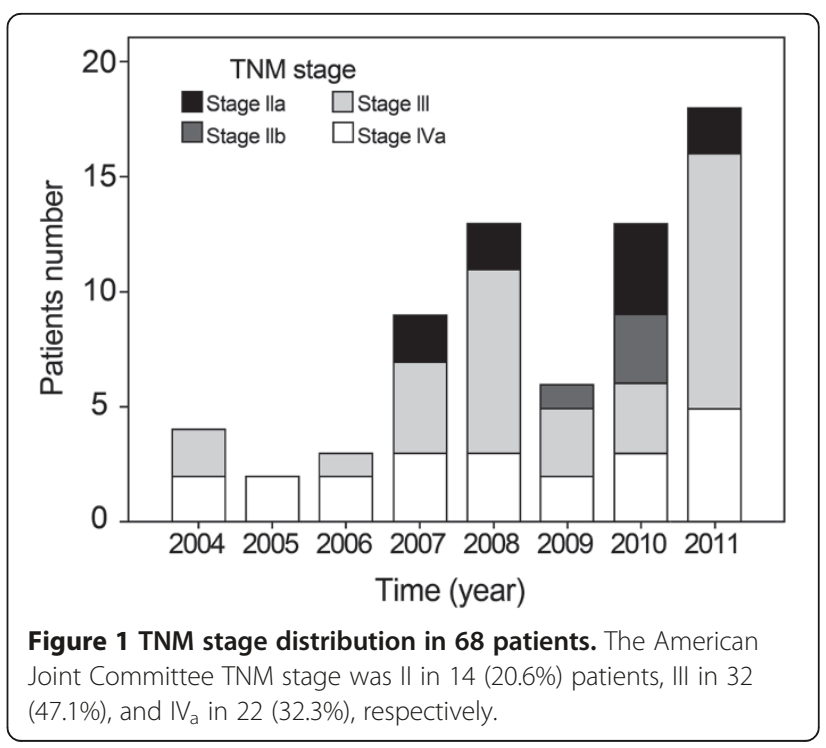


Table 1 Patient-, tumor- and treatment-related characteristics

\begin{tabular}{|c|c|c|}
\hline Characteristics & No. & $\%$ \\
\hline No. of patients & 68 & 100 \\
\hline \multicolumn{3}{|l|}{ Age (years) } \\
\hline Median & 63 & - \\
\hline Range & $40-75$ & - \\
\hline \multicolumn{3}{|l|}{ Gender } \\
\hline Male & 58 & 85.3 \\
\hline Female & 10 & 14.7 \\
\hline \multicolumn{3}{|l|}{ Performance status } \\
\hline KPS 70-80 & 52 & 76.5 \\
\hline KPS 90-100 & 16 & 23.5 \\
\hline \multicolumn{3}{|l|}{ AJCC TNM stage } \\
\hline Stage $\|_{a}$ & 10 & 14.7 \\
\hline Stage $\|_{b}$ & 4 & 5.9 \\
\hline Stage III & 32 & 47.1 \\
\hline Stage $\mathrm{IV}_{\mathrm{a}}$ & 22 & 32.3 \\
\hline \multicolumn{3}{|l|}{ Tumor length $(\mathrm{cm})$} \\
\hline Median & 5.0 & - \\
\hline Range & $2.0-11.5$ & - \\
\hline \multicolumn{3}{|l|}{ Tumor location } \\
\hline Cervical & 8 & 11.8 \\
\hline Upper-thoracic & 24 & 35.3 \\
\hline Mid-thoracic & 27 & 39.7 \\
\hline Lower-thoracic & 9 & 13.2 \\
\hline \multicolumn{3}{|l|}{${ }^{*}$ Regimens } \\
\hline 5-fluorouracil & 20 & 29.4 \\
\hline Capecitabine & 12 & 17.5 \\
\hline Pemetrexed & 32 & 47.1 \\
\hline
\end{tabular}

* Others treated with cisplatin plus vinorelbineis (1), gemcitabine (1), and docetaxel (2).

For patients with stage II-III, the 1-, 3-, and 5-year OS were $78.6 \%, 49.4 \%$, and $39.9 \%$, respectively, versus $68.3 \%, 41.0 \%$, and $15.4 \%$ for $\mathrm{IV}_{\mathrm{a}}$ patients, respectively. The Kaplan-Meier survival curve was presented in Figure 3. The difference in OS among patients with different clinical stages was not statistically significant (Chi-square $=0.180, p=0.671$ ). Similar result was also observed among patients receiving different chemotherapy regimens (Chi-square $=0.159$, $\mathrm{p}=0.690$ ) (Figure 4).

\section{Patterns of failure}

The crude patterns of failure were listed in Table 2. The incidence of any local recurrence, regional failure, and distant metastasis were $20.6 \%, 17.6 \%$, and $19.1 \%$, respectively. About twenty-nine percent (20/68) of the patients had local or/and regional disease presenting as the first failure, distant metastases as the first failure occurred in

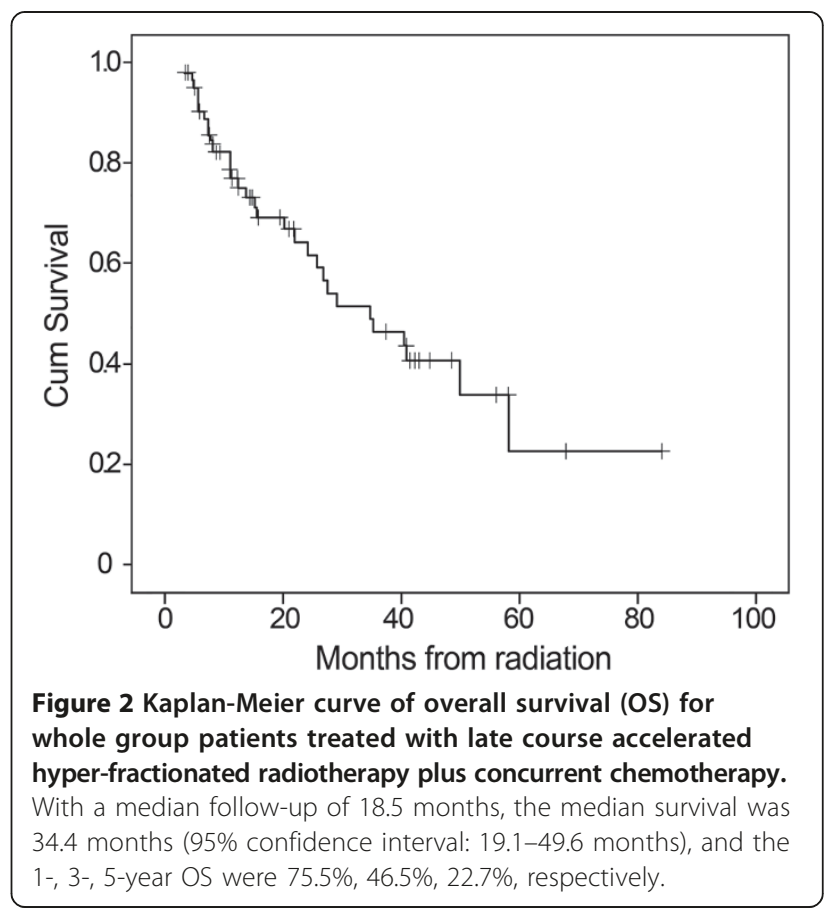

13 patients. The sites of distant metastases were: liver (4), bone (2), lungs (1), pleura (1), brain (1), and multi-organs (1). Moreover, another three patients developed distant lymph node metastases containing cervical (1), celiac (1), and retroperitoneal (1) parts.

\section{Toxicity}

The incidence of grade 3 or higher acute radiation toxicity was seen in Table 3. Esophagitis in Grade 3 was

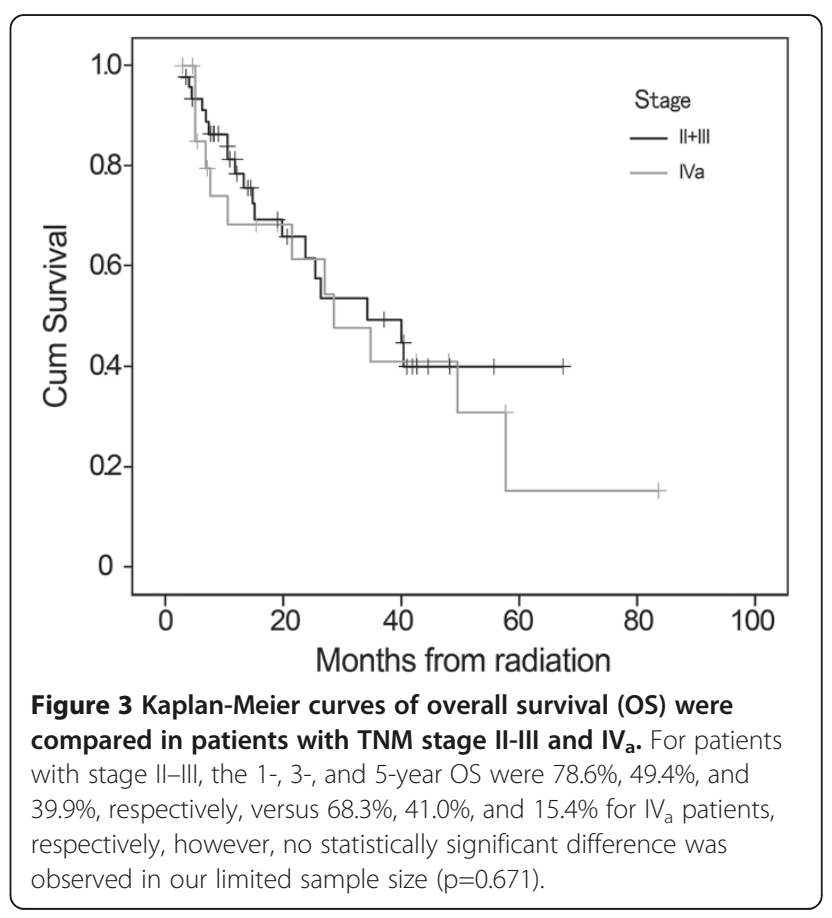




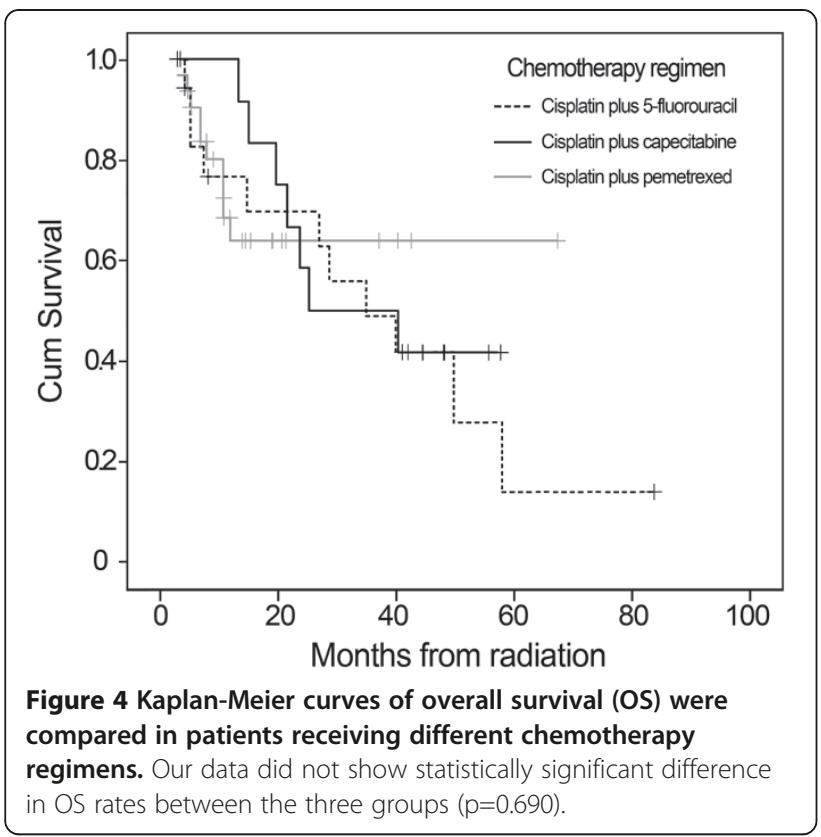

recorded in 18 patients (26.4\%). Leucopenia in grade 3-4 was recorded in 22 patients $(32.4 \%)$. No patients developed grade 3 and worse lung toxicity (pneumonitis). Treatment-related high-grade $(\geq 3)$ skin injury and gastrointestinal reaction were observed in 1 and 2 patients, respectively. One patient developed esophageal stenosis in grade 3, and another one had pulmonary fibrosis in grade 3. However, five patients died of late complications as displayed in Table 4, including gastrointestinal hemorrhage (4.4\%) and esophagus fistula (2.9\%).

\section{Discussion}

ESCC remains one of the most lethal carcinomas in China. The poor survival is mainly related to the advanced stages at diagnosis. The optimal management for locally advanced disease remains controversial. Surgery or RT alone is associated with a poor survival, usually less than $10 \%$ at 5 years [16]. Randomized studies [1,2] have demonstrated the survival advantage of concurrent

Table 2 Patterns of failure

\begin{tabular}{lll}
\hline Patterns of failure & No. & $\%$ \\
\hline Local recurrence only & 8 & 11.8 \\
\hline Regional failure only & 6 & 8.8 \\
\hline Locoregional failure & 4 & 5.9 \\
\hline Distant lymph node metastases only & 3 & 4.4 \\
\hline Distant organ metastasis only & 8 & 11.8 \\
\hline Locoregional failure plus distant metastasis & 2 & 2.9 \\
\hline Dead of complication & 5 & 7.4 \\
\hline Other diseases & 4 & 5.9 \\
\hline Unknown & 3 & 4.4 \\
\hline
\end{tabular}

chemoradiotherapy compared with RT alone for patients with squamous cell or adenocarcinoma of the esophagus. Although concurrently administered chemotherapy acts as a promoter of the locoregional effects of RT, the locoregional control remains unsatisfactory in RTOG 85-01 trail [1]. Dose escalation trial by RTOG 94-05 failed to improve the locoregional control as well [2]. It may thus be concluded that by simply increasing the local radiation dose cannot easily convert to survival benefits for esophageal carcinoma patients. Therefore, many efforts have been made to explore the more reasonable treatment schedules based on this thinking and understanding to radiobiology.

From last two decades, a further increase in localregional tumor control may be expected by augmenting radiation effects by altering fractionation schedule, because rapid tumor clonogen repopulation during treatment seems to be a cause of poor prognosis for cancer patients. One phase II study from Japan showed a promising result for ESCC patients treated with accelerated hyperfractionated RT plus 5-fluorouracil/cisplatin chemotherapy [17]. In China, Shi and their teams [18] initiated the study of LCAHRT for ESCC treatment, and yielded very encouraging results. Comparing with conventional fractionation (CF), the 5-year survival (34\% versus 15\%) and local control (55\% versus $21 \%$ ) were markedly improved with the LCAHRT regime. Henceforth, unremitting results from randomized and retrospective trials came out [19-23]. Recently, three independent meta-analysis from China strengthened the evidence of therapeutically beneficial of LCAHRT compared with CF for esophageal carcinoma $[5,24,25]$.

Because of unique geographical and pathologic features of esophageal carcinomas in China, furthermore, esophageal carcinomas tend to spread axially to regional lymphatics, producing morbidity and mortality from locoregional effects [1]. Based on the previous studies $[9,10]$, we supposed that elective HRLNR irradiation might be associated with lower nodal failure in advanced stage ESCC, and this hypothesis was supported by recent studies from Asian [11,12,26]. From another point of view, considering of high incidence of nodal failure in combined modality therapy, chemotherapy seems to play a limited role in preventing locoregional or distant nodal failure. Omitting ENI may be not reasonable for locally advanced stage ESCC patients, especially if the primary tumor located in lymphatic-rich regions [27] and PET/CT could not be incorporated in the planning of radiotherapy [28].

Previous study designed by Zhao et al. [22] enrolled 54 cases of local advanced stage ESCC with clinical stage $\mathrm{T}_{1-4} \mathrm{~N}_{0-1} \mathrm{M}_{0}$ treated with LCAHRT (41.4Gy/23 fractions followed by $27 \mathrm{~Gy} / 18$ fractions with $1.5 \mathrm{~Gy}$ per fraction, twice a day) and 2 cycles of concurrent chemotherapy with cisplatin $\left(25 \mathrm{mg} / \mathrm{m}^{2} /\right.$ day days $\left.1-3\right)$ plus 5 -FU (600 
Table 3 Treatment-related toxicity

\begin{tabular}{|c|c|c|c|c|c|}
\hline Treatment-related toxicity & Grade $0-1$ & Grade 2 & Grade 3 & Grade 4 & Grade 5 \\
\hline \multicolumn{6}{|l|}{ Acute toxicity } \\
\hline Lung & $67(98.5 \%)$ & $1(1.5 \%)$ & 0 & 0 & 0 \\
\hline Esophagus & $29(42.7 \%)$ & $21(30.9 \%)$ & $18(26.4 \%)$ & 0 & 0 \\
\hline Skin & $67(98.5 \%)$ & 0 & $1(1.5 \%)$ & 0 & 0 \\
\hline \multicolumn{6}{|l|}{ Hematologic } \\
\hline Hemoglobin & $60(88.2 \%)$ & $3(4.4 \%)$ & $4(5.9 \%)$ & $1(1.5 \%)$ & 0 \\
\hline Leucopenia & $20(29.4 \%)$ & $26(38.2 \%)$ & $20(29.4 \%)$ & $2(2.9 \%)$ & 0 \\
\hline Neutropenia & $53(77.9 \%)$ & $3(4.4 \%)$ & $12(17.7 \%)$ & 0 & 0 \\
\hline Thrombocytopenia & $48(70.6 \%)$ & $13(19.1 \%)$ & $5(7.4 \%)$ & $2(2.9 \%)$ & 0 \\
\hline Gastrointestinal & $57(83.8 \%)$ & $9(13.2 \%)$ & $2(2.9 \%)$ & 0 & 0 \\
\hline \multicolumn{6}{|l|}{ Late toxicity } \\
\hline Lung & $64(94.1 \%)$ & $3(4.4 \%)$ & $1(1.5 \%)$ & 0 & 0 \\
\hline Esophagus & $61(89.7 \%)$ & $4(5.9 \%)$ & $1(1.5 \%)$ & 0 & $2(2.9 \%)$ \\
\hline Heart & $66(97.1 \%)$ & $2(2.9 \%)$ & 0 & 0 & 0 \\
\hline
\end{tabular}

$\mathrm{mg} / \mathrm{m}^{2} /$ day days $\left.1-3\right)$. And they reported the median survival was 30.8 months (95\%CI, 17.6-44.1 months), Survival rates at 1,3 , and 5 years were $67 \%, 44 \%$, and $40 \%$, respectively. Twenty-six percent (14/54) of patients had locoregional disease presenting as the first failure, and distant metastases as the first failure occurred in $24 \%$ $(13 / 54)$. In our study, 40Gy/20 fractions delivered to primary and metastatic regional tumor(s) and HRLNR, and additional 19.6Gy/14 fractions in 1.4Gy per fraction, twice a day, were given to the boost volume. Cisplatin-based chemotherapy concurrently administered during the RT course. Our regimen improved median survival time from 30.8 to 34.4 months, and the OS at 1-, 3-year improved from $67 \%, 44 \%$ to $75.5 \%, 46.5 \%$, respectively. However, this trend was not observed at 5 -year (40\% vs. $22.7 \%)$. It should be noticed that approximately $32.3 \%$ of the population consisted of stage $\mathrm{IV}_{\mathrm{a}}$ cases, and $46 \%$ of eligible patients were enrolled between 2010 and 2011 (Figure 1) in our study, which may partially explain the relatively poor 5 -year OS. By subgroup analysis, for patients with stage II-III, the 5-year OS reached to $39.9 \%$, which was similar to the results of Zhao et al. [22]. Despite the study cohort consisted of a high proportion of patients with stage $I_{a}$, this regimen was associated with only twenty-nine percent of local or/and regional failure and nineteen percent of distant metastases. Previous studies (Table 5) focusing

Table 4 Treatment-related complications

\begin{tabular}{lll}
\hline Complications & No & \% \\
\hline Upper-gastrointestinal hemorrhage & 3 & 4.4 \\
\hline Esophagus-tracheal fistula & 2 & 2.9 \\
\hline
\end{tabular}

on LCAHRT regimen reported the patterns of failure from local/locoregional failure and distant metastasis were $12.5-41.8 \%$ and $15.4-34.9 \%$, respectively [18-23] in patients with TNM stage limited to I-III.

Regarding tolerance in our study, high-grade $(\geq 3)$ acute esophagitis and leucopenia were seen in $26.4 \%$ and $32.4 \%$ of patients, respectively. Similar findings were reported by Zhao et al. [22]. The higher rates of acute toxicities may be related to this treatment scheme. Our approach allowed us to avoid potential micrometastasis of lymphatics, nevertheless, it was gained at the expense of early toxicities. Therefore, how to minimize the damage to the sensitive normal tissues within irradiated fields without sparing cancer is a big challenge. Recent innovation of RT technology has made it possible to use sophisticated rotational intensity-modulated RT. This can deliver intensified radiation doses to the tumor while minimizing the doses to the normal tissues [29]. Acceleration of radiation treatment involves the delivery of the target dose in less time, and is analogous to the concept of dose-intensity in the delivery of cytotoxic chemotherapy. In order to prevent late toxicity, we reduced the dosage of per fraction (1.4Gy per fraction twice day). The interval between daily fractions (typically $\geq 6$ hours) provides normal tissues with time to repair sublethal radiation damage, which may be responsible for the lower rate of late lung toxicity in our study. Notably, treatment-related upper-gastrointestinal hemorrhage (4.4\%) and esophagus-tracheal fistula (2.9\%) were relatively higher, which should be paid much attention. Although the reason for the higher incidence of such complications was unknown, we suspected that it might be association with advanced $\mathrm{T}$ stage in our cohort of patients. 
Table 5 Survival and toxicities of patients undergoing late course accelerated hyper-fractionated radiotherapy for esophageal squamous cell carcinoma

\begin{tabular}{|c|c|c|c|c|c|c|c|c|}
\hline First author & Study & No. of patients & TNM stage & Treatment scheme & Overall survival & Locol control & Treatment failure & Toxicity (Grade $\geq 3$ \\
\hline \multirow[t]{2}{*}{ Shi XH [18] } & \multirow[t]{2}{*}{ Prospective } & \multirow[t]{2}{*}{43} & \multirow[t]{2}{*}{$\mathrm{T}_{1-4} \mathrm{~N}_{0-1} \mathrm{M}_{0}$} & \multirow{2}{*}{$\begin{array}{l}\text { 41.4Gy/23fx followed by } 27 \mathrm{~Gy} / 18 \mathrm{fx} \\
\text { with } 1.5 \mathrm{~Gy} \text {, bid }\end{array}$} & \multirow[t]{2}{*}{5 -year 34\% } & \multirow[t]{2}{*}{5 -year 55\% } & LR $41.8 \%(18 / 43)$ & PI 27.9\% (12/43) \\
\hline & & & & & & & DM 18.6\% (8/43) & El 34.9\% (15/43) \\
\hline \multirow[t]{5}{*}{ Wang Y [19] } & \multirow[t]{5}{*}{ Prospective } & \multirow[t]{5}{*}{52} & \multirow[t]{5}{*}{$\mathrm{T}_{1-4} \mathrm{~N}_{0-1} \mathrm{M}_{0}$} & \multirow{5}{*}{$\begin{array}{l}41.4 \mathrm{~Gy} / 23 \mathrm{fx} \text { followed by } 27 \mathrm{~Gy} / 18 \mathrm{fx} \\
\text { with } 1.5 \mathrm{~Gy}, \text { bid }\end{array}$} & \multirow[t]{2}{*}{1 -year $80.0 \%$} & \multirow[t]{2}{*}{1 -year $80.7 \%$} & \multirow[t]{2}{*}{ LRF $13.5 \%(7 / 52)$} & PI 3.8\% (2/52) \\
\hline & & & & & & & & El 9.6\% (5/52) \\
\hline & & & & & \multirow[t]{3}{*}{3 -year $41.2 \%$} & \multirow[t]{3}{*}{3 -year $57.1 \%$} & \multirow[t]{3}{*}{ DM 15.4\% (8/52) } & ES 1.9 \% (1/52) \\
\hline & & & & & & & & PF 0\% (0/48) \\
\hline & & & & & & & & EH 3.8\% (2/52) \\
\hline \multirow[t]{4}{*}{ Zhao KL [20] } & \multirow[t]{4}{*}{ Retrospective } & \multirow[t]{4}{*}{56} & \multirow[t]{4}{*}{$\mathrm{T}_{1-2} \mathrm{~N}_{0} \mathrm{M}_{0}$} & \multirow{4}{*}{$\begin{array}{l}\text { 41.4Gy/23fx followed by } 27 \mathrm{~Gy} / 18 \mathrm{fx} \\
\text { with } 1.5 \mathrm{~Gy} \text {, bid }\end{array}$} & 1 -year $90.9 \%$ & 1 -year 90.9\% & LR $12.5 \%(7 / 56)$ & PI 5.4 \% (3/56) \\
\hline & & & & & 3 -year $54.6 \%$ & 3 -year $84.5 \%$ & \multirow[t]{3}{*}{ DM 21.4\% (12/56) } & El $10.7 \%(6 / 56)$ \\
\hline & & & & & & & & ES $1.8 \%(/ 56)$ \\
\hline & & & & & 5 -year $47.8 \%$ & 5-year $84.5 \%$ & & PF $1.8 \%$ (/56) \\
\hline \multirow[t]{4}{*}{ Zhao KL [21] } & \multirow[t]{4}{*}{ Retrospective } & \multirow[t]{4}{*}{201} & \multirow[t]{4}{*}{$\mathrm{T}_{1-4} \mathrm{~N}_{0-1} \mathrm{M}_{0}$} & \multirow{4}{*}{$\begin{array}{l}41.4 \mathrm{~Gy} / 23 \mathrm{fx} \text { followed by } 27 \mathrm{~Gy} / 18 \mathrm{fx} \\
\text { with } 1.5 \mathrm{~Gy} \text {, bid }\end{array}$} & 1-year 73\%, & 1 -year $77 \%$ & \multirow[t]{2}{*}{ LRF $38.4 \%(77 / 201)$} & El 15.4\% (31/201) \\
\hline & & & & & & & & PI 7.0\% (14/201) \\
\hline & & & & & 3 -year 34\%, & 3 -year 58\% & \multirow[t]{2}{*}{ DM 34.9\% (70/201) } & \multirow[t]{2}{*}{ EF 0.5\% (1/201) } \\
\hline & & & & & 5 -year 26\% & 5 -year 56\% & & \\
\hline \multirow[t]{4}{*}{ Zhao KL [22] } & Prospective & 54 & $\mathrm{~T}_{1-4} \mathrm{~N}_{0-1} \mathrm{M}_{0}$ & 41.4Gy/23fx followed by $27 \mathrm{~Gy} / 18 \mathrm{fx}$ with $1.5 \mathrm{~Gy}$, & 1-year 67\%, & 1 -year $84 \%$ & LRF $25.9 \%(14 / 54)$ & El $24.1 \%(13 / 54)$ \\
\hline & & & & & & & & PI 5.5\% (3/54) \\
\hline & & & & & 3-year 44\%, & 3 -year $74 \%$ & & PF $14.8 \%(8 / 54)$ \\
\hline & & & & & 5 -year $40 \%$ & 5 -year $67 \%$ & DM 24\% (13/54) & ES $3.7 \%(2 / 54)$ \\
\hline Wang JH [23] & Prospective & 48 & $\mathrm{~T}_{1-4} \mathrm{~N}_{0-1} \mathrm{M}_{0}$ & 40Gy/20fx followed by 21-27 Gy/14-18fx & 1 -year $79.2 \%$ & 1 -year $81.3 \%$ & LR $35.4 \%(17 / 48)$ & PI 33.33\% (16/48) \\
\hline & & & & with 1.5Gy, bid & & & & El 27.1\% (13/48) \\
\hline & & & & & 3 -year $43.8 \%$ & 3 -year $50.0 \%$ & DM $16.7 \%(8 / 48)$ & ES 14.6\% (7/48) \\
\hline & & & & & & & & PF 0\% (0/48) \\
\hline
\end{tabular}

Note: distant metastasis-DM; local recurrence-LR; locoregional failure-LRF; esophagitis-El; pneumonitis-Pl; pulmonary fibrosis-PF; esophageal stenosis-ES; esophageal hemorrhage-EH; esophagus fistula-EF; fractions$\mathrm{fx}$; twice a day-bid; concurren chemotherapy-CHT. 
Several strengths and limitations should be noted. This was a single center study with a relatively small sample size, which may limit the generalizability of our findings. This study cohort consisted of a higher proportion of stage $\mathrm{IV}_{\mathrm{a}}$ who had worse prognosis. Moreover, a variety of cisplatin-based chemotherapy regimens were enrolled, although OS rate was not associated with combined regimens. The chemotherapy agents are usually 5 -fluorouracil and cisplatin. Recently, capecitabine and pemetrexed have been introduced in phase I and II trials and the preliminary results are promising [13]. Therefore, how to best combine chemotherapy and accelerated radiotherapy regimens to maximize local control and survival is an important question. Further trials and observation confirming the efficiency of LCAHRT concurrently with these chemotherapy regimens are still needed. At last, this accelerated radiation scheme is broadly used as a standard treatment for locally advanced ESCC and non-small cell lung cancer in China, however, has not met with widespread clinical acceptance in the United States or Europe probably because of higher acute toxicity, and the use of twice fractions per day.

In conclusion, this phase II study with limited number of patients demonstrated that ENI LCAHRT concurrently with $\mathrm{CHT}$ was generally tolerated, and the treatment outcome was satisfactory. Although these results by this interim analysis were not sufficient to confirm the impact on ESCC treatment with this regimen, the results in our cohort patients with a higher proportion of advanced stage were compared favorably with those of previous studies. Further observation with longer time follow up and randomized phase III trial is currently underway.

\section{Abbreviations}

LCAHRT: Late course accelerated hyper-fractionated radiotherapy;

ESCC: Esophageal squamous cell carcinoma; ENI: Elective lymph node irradiation.

\section{Competing interests}

The authors declare that they have no competing interest.

\section{Authors' contributions}

DW, JY and MS carried out the manuscript writing; JZ participated in statistical analysis; BL and LZ conceived and designed this study; $H G, T Z, Y W$, $\mathrm{WH}, \mathrm{ZW}, \mathrm{HL}$, and ZZ helped to collect data. All authors read and approved the final manuscript.

\section{Acknowledgment}

This work was supported in part by 30670617 from National Nature Science Foundation of China and 2007HZ102 from Medicine and Public Health Project of Shandong Province.

\section{Author details}

'Department of Radiation Oncology, Shandong Cancer Hospital, Shandong Academy of Medical Sciences, Jinan, China. ${ }^{2}$ Department of Gastroenterology, Qidu Hospital affiliated to Qingdao Medical College, Zibo, China. ${ }^{3}$ Jinan Central Hospital affiliated to Shandong University, Jinan, China.

Received: 3 October 2012 Accepted: 23 April 2013

Published: 2 May 2013

\section{References}

1. Cooper JS, Guo MD, Herskovic A: Chemoradiotherapy of locally advanced esophageal cancer: long-term follow-up of a prospective randomized trial (RTOG 85-01). Radiation Therapy Oncology Group. JAMA 1999, 281:1623-1627.

2. Minsky BD, Pajak TF, Ginsberg RJ: INT 0123 (Radiation Therapy Oncology Group 94-05) phase III trial of combined-modality therapy for esophageal cancer: high-dose versus standard-dose radiation therapy. J Clin Oncol 2002, 20:1167-1174.

3. Fowler JF, Lindstrom MJ: Loss of local control with prolongation in radiotherapy. Int J Radiat Oncol Biol Phys 1992, 23:457-467.

4. Withers HR, Taylor JM, Maciejewski B: The hazard of accelerated tumor clonogen repopulation during radiotherapy. Acta Oncol 1988, 27:131-146.

5. Zhang YW, Chen L, Bai Y: Long-term outcomes of late course accelerated hyper-fractionated radiotherapy for localized esophageal carcinoma in Mainland China: a meta-analysis. Dis Esophagus 2011, 24:495-501.

6. Pan ZQ, He XY, Guo XM: A Phase III Study of Late Course Accelerated Hyperfractionated Radiotherapy Versus Conventionally Fractionated Radiotherapy in Patients With Nasopharyngeal Carcinoma. Am J Clin Oncol 2012, 35:600-605.

7. He XY, Liu TF, He SQ: Late course accelerated hyperfractionated radiotherapy of nasopharyngeal carcinoma (LCAF). Radiother Oncol 2007, 85:29-35.

8. Chen M, Chen YY, Bao Y: Neoadjuvant chemotherapy followed by late-course accelerated hyperfractionated radiation therapy for locally advanced non-small-cell lung cancer: long-term results of a phase I/II clinical trial. Clin Lung Cancer 2005, 6:304-309.

9. Akiyama $\mathrm{H}$, Tsurumaru M, Udagawa H: Radical lymph node dissection for cancer of the thoracic esophagus. Ann Surg 1994, 220:364-372. discussion 372-373.

10. Kato $H$, Watanabe $H$, Tachimori $Y$ : Evaluation of neck lymph node dissection for thoracic esophageal carcinoma. Ann Thorac Surg 1991, 51:931-935.

11. Onozawa M, Nihei K, Ishikura S: Elective nodal irradiation (ENI) in definitive chemoradiotherapy (CRT) for squamous cell carcinoma of the thoracic esophagus. Radiother Oncol 2009, 92:266-269.

12. Yamashita $H$, Okuma $K$, Wakui R: Details of recurrence sites after elective nodal irradiation (ENI) using 3D-conformal radiotherapy (3D-CRT) combined with chemotherapy for thoracic esophageal squamous cell carcinoma-a retrospective analysis. Radiother Oncol 2011, 98:255-260.

13. Jatoi A, Soori G, Foster NR: Phase II study of preoperative pemetrexed, carboplatin, and radiation followed by surgery for locally advanced esophageal cancer and gastroesophageal junction tumors. J Thorac Oncol 2010, 5:1994-1998.

14. Li BS, Gong HY, Huang W: Phase I study of concurrent selective lymph node late course accelerated hyper-fractionated radiotherapy and pemetrexed, cisplatin for locally advanced esophageal squamous cell carcinoma. Dis Esophagus 2011, 24:251-257.

15. Li BS, Zhou T, Wang ZT: Phase I study of concurrent selective lymph node late course accelerated hyper-fractionated radiotherapy and Capecitabine, Cisplatin for locally advanced esophageal squamous cell carcinoma. Radiother Oncol 2009, 93:458-461.

16. Nguyen NP, Leonardo JM, Karlsson U: Preoperative chemotherapy and radiation for advanced esophageal carcinoma: comparison between once a day radiation and hyperfractionation, a single-institution experience. Am J Clin Oncol 2002, 25:358-364.

17. Jeremic B, Shibamoto $Y$, Acimovic L: Accelerated hyperfractionated radiation therapy and concurrent 5 -fluorouracil/cisplatin chemotherapy for locoregional squamous cell carcinoma of the thoracic esophagus: a phase II study. Int J Radiat Oncol Biol Phys 1998, 40:1061-1066.

18. Shi XH, Yao W, Liu T: Late course accelerated fractionation in radiotherapy of esophageal carcinoma. Radiother Oncol 1999, 51:21-26.

19. Wang Y, Shi XH, He SQ: Comparison between continuous accelerated hyperfractionated and late-course accelerated hyperfractionated radiotherapy for esophageal carcinoma. Int J Radiat Oncol Biol Phys 2002, 54:131-136

20. Zhao KL, Wang Y, Shi XH: Late course accelerated hyperfractionated radiotherapy for clinical T1-2 esophageal carcinoma. World J Gastroenterol 2003, 9:1374-1376

21. Zhao KL, Shi $X H$, Jiang GL: Late-course accelerated hyperfractionated radiotherapy for localized esophageal carcinoma. Int J Radiat Oncol Biol Phys 2004, 60:123-129. 
22. Zhao KL, Shi XH, Jiang GL: Late course accelerated hyperfractionated radiotherapy plus concurrent chemotherapy for squamous cell carcinoma of the esophagus: a phase III randomized study. Int I Radiat Oncol Biol Phys 2005, 62:1014-1020.

23. Wang JH, Lu XJ, Zhou J: A randomized controlled trial of conventional fraction and late course accelerated hyperfraction three-dimensional conformal radiotherapy for esophageal cancer. Cell Biochem Biophys 2012, 62:107-112.

24. Liu CX, Li XY, Gao XS: Meta-analysis of late course accelerated hyperfractionated radiotherapy combined with FP chemotherapy for esophageal carcinoma. Chin J Cancer 2010, 29:889-899.

25. Zhou ZG, Gao XS, Qiao XY: Literature analysis of radiotherapy for esophageal cancer in China. Chin J Cancer 2010, 29:873-881.

26. Hsu FM, Lee JM, Huang PM: Retrospective analysis of outcome differences in preoperative concurrent chemoradiation with or without elective nodal irradiation for esophageal squamous cell carcinoma. Int J Radiat Oncol Biol Phys 2011, 81(4):e593-599.

27. Balamucki CJ, Amdur RJ, Werning JW: Adenoid cystic carcinoma of the head and neck. Am J Otolaryngol 2012, 33:510-518.

28. Kolodziejczyk M, Kepka L, Dziuk M: Impact of [18F]fluorodeoxyglucose PET-CT staging on treatment planning in radiotherapy incorporating elective nodal irradiation for non-small-cell lung cancer: a prospective study. Int J Radiat Oncol Biol Phys 2011, 80:1008-1014.

29. Wang D, Yang Y, Zhu J: 3D-conformal RT, fixed-field IMRT and RapidArc, which one is better for esophageal carcinoma treated with elective nodal irradiation. Technol Cancer Res Treat 2011, 10:487-494.

doi:10.1186/1748-717X-8-108

Cite this article as: Wang et al: Elective lymph node irradiation late course accelerated hyper-fractionated radiotherapy plus concurrent cisplatin-based chemotherapy for esophageal squamous cell carcinoma: a phase II study. Radiation Oncology 2013 8:108.

\section{Submit your next manuscript to BioMed Central and take full advantage of:}

- Convenient online submission

- Thorough peer review

- No space constraints or color figure charges

- Immediate publication on acceptance

- Inclusion in PubMed, CAS, Scopus and Google Scholar

- Research which is freely available for redistribution 